\title{
RESENHA
}

\section{JOHNSON, Susan Moore \& PAPAY, John. Redesigning Teacher Pay - A System for the Next Generation of Educators. EPI, volume 2: USA, 2009}

\section{Por Luiza Freire ${ }^{1}$}

Esta resenha tem como objetivo apresentar e divulgar uma das produções acadêmicas recentes estadunidenses a respeito da remuneração dos docentes da educação básica. Susan Moore Johnson e John Papay apresentam aos leitores os resultados das pesquisas desenvolvidas nos Estados Unidos pelo Instituto de Economia Política (EPI). O Instituto é responsável por publicar uma série de pesquisas destinadas a compreender como as políticas educacionais e de remuneração de professores tem impactado no cotidiano da profissão nos últimos anos naquele país. Neste segundo volume os autores demonstram analiticamente a estrutura da remuneração norte-americana frente as mudanças implementadas no governo de Barack Obama. Políticas estas que concentram-se na identificação, recrutamento, motivação e retenção de professores altamente eficazes.

$\mathrm{Na}$ introdução os autores abordam a recente história da política educacional estadunidense e apontam para os principais componentes responsáveis pelos planos educacionais e que orientam as novas diretrizes para o pagamento dos docentes, tais como, os planos baseados no pagamento por performance e através de resultados dos testes padronizados. Os autores indicam que grande parte destas políticas derivaram da preocupação tanto da iniciativa privada quanto do governo nacional em melhorar a qualidade no interior das escolas. Estas instituições partiram em essência da prerrogativa, lançada pelo então presidente Barack Obama, em 2009, para a melhoria dos programas de formação docente que "(...)É hora de começar a premiar os bons professores, [e] parar de inventar desculpas para os maus” (New York Daily News, 2009). Nesse contexto é possível identificar que a nova intenção entre os reformadores da educação surgiu sugerindo que este sistema atual está "fora de moda". O sistema tradicional, segundo os autores em análise sobre os reformistas, não consegue atrair os melhores graduados e proporcionar na prática dos professores incentivos na produção de resultados entendido pelos autores como qualidade nas escolas. A série de livros reúne especialistas da educação e das ciências sociais para analisar os principais aspectos dessas políticas.

Neste volume é possível entender o processo derivado a partir do ano de dois mil e nove (2009), basicamente em resposta as políticas reformistas que alguns estados e distritos escolares começaram a experimentar os novos planos utilizando-se da aplicação em formato pay-for-performance, onde os professores são compensados, pelo menos em parte, pela sua contribuição para os (bons) resultados dos testes padronizados dos alunos.

O livro é subdivido em introdução, dois capítulos dedicados à análise e, por fim, as conclusões dos autores. No primeiro capítulo os autores apontam a política do pagamento por performance (pay-for-performance) e segundo eles esta ação concentra-se em uma cadeia de programas. Nesta rede incluem-se as estratégias de compensação salarial, a tentativa de aproximação da rede do pagamento por resultados e como esta prática se dá na realidade das escolas. Os autores anunciam e fornecem uma estrutura simples para comparar,

1 Mestre em Educação pela UFPR e bolsista de Doutorado (CAPES) no Núcleo de Políticas Educacionais (NuPE) da Universidade Federal do Paraná. E-mail: luizafreire80@gmail.com 
projetar e avaliar remuneração por desempenho através dos planos de educação. Um panorama abrangente, motivado pelas pesquisas em economia e psicologia sobre o impacto dos incentivos sobre o comportamento do trabalhador e que é aplicado a vários planos de pagamento de desempenho conhecidos atualmente e utilizados em grandes distritos escolares urbanos nos Estados Unidos.

A segunda parte é dedicada a análise referente aos pagamentos e ao plano de carreira, estes itens como uma nova proposta ou um novo olhar para as futuras gerações de professores. Os autores abordam os estágios do plano de carreira, o olhar acerca dos fundos remetidos à carreira docente, os incentivos locais e prêmios que compõe a remuneração e como se dá a implementação do plano atualmente em alguns distritos e cidades americanas. A conclusão é inacabada demonstrando a necessidade de pesquisas mais avançadas no campo, pois os impactos das políticas de remuneração ainda são recentes e difíceis de mensurar em resultados concretos. Os autores apontam para algumas hipóteses para um futuro próximo na análise dos estados e/ou distritos onde os planos apresentam no momento resultados mais favoráveis após a implementação dos planos de carreira reconfigurados dentro da lógica dos testes padronizados.

Por fim é preciso alertar que os autores indicam um trabalho de pesquisa mais minucioso, que proporcione uma visão a longo prazo da execução dos planos, oferecendo um plano de carreira baseado no que é destinado, ou seja, exclusivamente a melhorar o capital humano na profissão docente. As últimas reformas remuneração norte-americanas demonstraram o volume de expressões e ações utilizadas para denominar as diferentes formas de pagamento da atividade docente, tais como, o pay-for-performance, a remuneração profissional, o pagamento por mérito, e a remuneração baseada em desempenho. Johnson\&Papay fornecem nesta obra uma estrutura simples, todavia rica, analítica, que permite identificar claramente as dimensões dos planos de remuneração por desempenho. Eles sugerem que a remuneração baseada no desempenho deve antes ser parte de uma estratégia de capital humano bem concebido para garantir um bom desenvolvimento da atividade docente através de todas as fases de sua carreira.

Em todas as passagens da obra e especialmente no desfecho os autores apontam que, como na maioria das reformas na remuneração dos professores recentes, ainda é muito cedo para avaliar empiricamente os efeitos e/ou impactos destas medidas sobre o desempenho e o mercado de trabalho para os professores estadunidenses. Os dois estudos neste volume percorrem um longo caminho para identificar as dimensões de pay-for-performance que merecem maior atenção por parte dos pesquisadores, policy makers e decisores políticos nos Estados Unidos e nos países que tem como foco a qualidade na educação. 